\title{
Effects of inclusion level and amino acid supplementation on energy values of soybean oil determined with difference or regression methods in growing pigs
}

\author{
Qiuyun Wang ${ }^{1, a}$, Chengfei Huang ${ }^{1, a}$, Mei Liư ${ }^{2}$, Ling Liu', and Shuai Zhang ${ }^{1, *}$
}

\author{
* Corresponding Author: Shuai Zhang \\ Tel: +86-10-62731109, Fax: +86-10-62733688, \\ E-mail: zhangshuai16@cau.edu.cn \\ ${ }^{1}$ State Key Laboratory of Animal Nutrition, Ministry of \\ Agriculture Feed Industry Centre, China Agricultural \\ University, Beijing 100193, China \\ ${ }^{2}$ Milk and Dairy Product Inspection Center of the \\ Ministry of Agriculture, Beijing 100193, China \\ a These authors contributed equally to this work. \\ ORCID \\ Qiuyun Wang \\ https://orcid.org/0000-0003-1492-8857 \\ Chengfei Huang \\ https://orcid.org/0000-0002-4943-1472 \\ Mei Liu \\ https://orcid.org/0000-0002-0151-7189 \\ Ling Liu \\ https://orcid.org/0000-0002-8832-9366 \\ Shuai Zhang \\ https://orcid.org/0000-0001-5435-2640
}

Submitted Dec 14, 2018; Revised Jan 18, 2019; Accepted Mar 7, 2019
Objective: This study was conducted to evaluate the effects of inclusion level and amino acid (AA) supplementation on energy values of soybean oil (SO) as determined by difference method or regression method when fed to growing pigs.

Methods: Thirty-six barrows (initial body weight: $28.0 \pm 1.3 \mathrm{~kg}$ ) were randomly assigned to one of 6 dietary treatments, which included 2 control diets formulated using a basal diet with or without AA supplementation, and 4 experimental diets with $5 \%$ or $10 \%$ SO addition in the 2 control diets, respectively. All pigs were individually housed in metabolism crates for $19 \mathrm{~d}$, and during the last $5 \mathrm{~d}$, total urine and feces production were collected. The nutrient digestibility in diets and the digestible energy (DE) and metabolizable energy (ME) values of SO were determined using the difference method and the regression method, respectively. Results: Our results showed that there were no interaction effects $(p>0.05)$ between AA supplementation and SO inclusion levels on energy values of SO and dietary nutrient digestibility. The $\mathrm{DE}$ and $\mathrm{ME}$ values of $\mathrm{SO}$ determined by the difference method were not affected $(p>0.05)$ by AA supplementation, however, the ME value of $S O$ increased $(p<0.05)$ as the inclusion level of SO increased. Moreover, the energy values of SO determined using the regression method were close to those determined using difference method with $10 \% \mathrm{SO}$ inclusion, but were greater than those obtained using difference method with 5\% SO inclusion. Conclusion: We concluded that the $\mathrm{DE}$ and $\mathrm{ME}$ values of $\mathrm{SO}$ increased with the inclusion level but were not affected by AA supplementation in the range of $0 \%$ to $10 \%$. The difference method can substitute for the regression method to determine the $\mathrm{DE}$ and $\mathrm{ME}$ values of SO when the inclusion level is $10 \%$, but not at $5 \%$ inclusion level.

Keywords: Amino Acid; Difference Method; Energy; Regression Method; Soybean Oil

\section{INTRODUCTION}

Energy is the most expensive nutritional component in animal diets. As an important energy source, lipid is commonly included in swine diets to improve the growth rate and feed efficiency of pigs [1,2]. Dietary lipid supplementation can also improve the digestibility and utilization of other nutrients in diets [3]. Therefore, it is important to accurately evaluate energy values of dietary lipids. Adequate and balanced amino acid (AA) content is another vital nutritional concern in swine diets. Crystalline AA supplementation in diets can influence energy utilization, feed intake, growth performance and carcass quality of pigs $[4,5]$, as well as, affect nitrogen deposition and utilization [6,7].

There are discrepancies in the energy value or soybean oil (SO) among different national and regional feed databases [8-11], which could be attributed to SO inclusion level, the basal diet composition, the processing technique of SO [9,12-14]. Previous work conducted 
by our research group reported the effect of basal diet type (corn-soybean meal diet vs. corn starch-casein diet) on digestible energy $(\mathrm{DE})$ and metabolizable energy $(\mathrm{ME})$ values of SO, and the results showed that the basal diet type did not affect the energy values of SO [15]. Another study explored the effects of AA supplementation and inclusion level on DE and $\mathrm{ME}$ value of soybean meal, and concluded that both inclusion level and AA supplementation influenced the energy values of soybean meal in pigs [16]. To our knowledge, no previous literature has reported the combined effects of inclusion level and AA supplementation on the energy value of SO.

The regression method is commonly used to evaluate the energy value of dietary lipid sources such as $\mathrm{SO}$ and canola oil $[2,17,18]$. The difference method, an indirect approach, is also used to assess the DE and ME values of feedstuff [19]. However, the lipid source inclusion level is typically limited (i.e. $5 \%$ to $10 \%$ ) when using the difference method. At low inclusion levels, evaluation and efficiency would be lower than that of high inclusion level, though low inclusion level was close to actual production. As a result, the evaluation accuracy and efficiency may be influenced by the basal diet composition. To our knowledge, no studies have investigated the discrepancy between the regression and difference methods on determination of SO energy values in growing pigs especially when crystalline AA is supplied in basal diet.

Therefore, the objective of this study was to evaluate the effect of AA supplementation, SO inclusion level, and experiential method on determination of $\mathrm{DE}$ and $\mathrm{ME}$ values of $\mathrm{SO}$ in growing pigs.

\section{MATERIALS AND METHODS}

The animal trial was conducted in the Metabolism Laboratory at the China Agricultural University Animal Experimental Base (Fengning, China). The protocol for the experiment was reviewed and approved by the Institutional Animal Care and Use Committee at China Agricultural University (Beijing, China).

\section{Animals, diets, and experimental design}

Thirty-six crossbred barrows (Duron $\times$ Landrace $\times$ Yorkshire) with initial body weight (BW) of $28.0 \pm 1.3 \mathrm{~kg}$ were randomly assigned to one of six dietary treatments, with six replicated pigs per treatment. The dietary treatments included two control diets formulated as a corn-soybean meal basal diet with $(\mathrm{AA}+)$ or without $(\mathrm{AA}-)$ crystalline lysine, methionine, threonine, tryptophan and valine supplementation, and four experimental diets where SO was added at $5 \%$ or $10 \%$ SO in each of these two control diets. Although the inclusion level of SO in a normal diet used in the actual production is usually less than $5 \%$, the low substitution rate would lead to high standard errors when using the difference method. That is the reason why previous studies tended to use regression method to evaluate the energy values of lipids $[2,17,18]$. Therefore, the higher inclusion level (5\% and 10\%) was used in this study to ensure a stable and accurate result, as compared with the inclusion levels used in the previous studies $[9,15]$. The four experimental diets were made by thoroughly mixing $5 \%$ or $10 \%$ SO with $95 \%$ or $90 \%$ basal diets (AA+ or AA-). The SO used was food-graded class four lipid and was obtained from the China Agriculture University Animal Experimental Base (Fengning, China). The energy content, AA levels, and other nutrients in the three AA+ diets were formulated to exceed the nutrient requirement for $25 \mathrm{~kg}$ pigs in NRC [11]. Corn replaced crystalline lysine in AA- diets. Ingredient compositions of the two control diets and the analyzed chemical compositions of the SO used in this study are listed in Table 1 and 2 , respectively.

All pigs were individually housed in stainless-steel metabolism crates $(1.4 \times 0.7 \times 0.6 \mathrm{~m})$ with ad libitum access to water during the animal trial. The experiment lasted for 19 days, which included a 14-d period for adaptation to crates and diets, followed by a 5 -d period for total feces and urine collection. Commercial diets were provided at the beginning of the experiment, and were gradually replaced by the treatment diets during the first 7-d of the adaptation period. On $\mathrm{d} 8$, pigs were weighted and daily feed allotment was set at $4 \%$ of BW, in two equal meals 08:00 $\mathrm{h}$ and 14:00 $\mathrm{h}$.

\section{Sample collection}

During the last 5 days, total but separate collections of feces and urine were completed twice daily according to the methods described by Su et al [9]. Feces were placed into plastic bags and stored at $-20^{\circ} \mathrm{C}$. At the end of the collection period, the 5 - $\mathrm{d}$ fecal production from each pig was pooled and weighed and a $350 \mathrm{~g}$ sub-sample was taken and dried in a forced-draft oven at $65^{\circ} \mathrm{C}$ for $72 \mathrm{~h}$. To limit microbial growth and ammonia loss in the collected urine, approximately $50 \mathrm{~mL}$ of $6 \mathrm{~N} \mathrm{HCl}$ was added to collection containers during the urine collection, and the urine samples were stored at $-20^{\circ} \mathrm{C}$ immediately after collection. At the end of the collection period, total urine volume was recorded and sub-samples $(4 \mathrm{~mL})$ were taken and dried at $65^{\circ} \mathrm{C}$ for $8 \mathrm{~h}$ with quantitative filter paper in crucibles for energy determination.

\section{Chemical analysis}

The fatty acid composition of SO was determined by high performance gas chromatography (6890 series, Agilent Technologies, Wilmington, DE, USA), following the method of Sukhija and Palmquist [20] with modifications. The characteristics of SO were determined according to AOCS [21] methods: $p$-Anisidine content was determined by AOCS Cd 18-90; the free fatty acid value was acquired by AOCS Ca $5 \mathrm{~A}-$ 
Table 1. Ingredient and chemical compositions of the control diets used in the experiment (\%, as-fed basis)

\begin{tabular}{|c|c|c|}
\hline \multirow{2}{*}{ Items } & \multicolumn{2}{|c|}{ Control diets ${ }^{1)}$} \\
\hline & $\mathrm{AA+}$ & $A A-$ \\
\hline Corn $(\%)$ & 73.81 & 74.85 \\
\hline Soybean meal (\%) & 22.00 & 22.00 \\
\hline Soybean oil (\%) & 0.00 & 0.00 \\
\hline Choline chloride (\%) & 0.05 & 0.05 \\
\hline Dicalcium phosphate (\%) & 1.25 & 1.25 \\
\hline Calcium carbonate (\%) & 1.05 & 1.05 \\
\hline Sodium chloride (\%) & 0.30 & 0.30 \\
\hline L-Lys HCl (\%) & 0.54 & 0.00 \\
\hline DL-Met (\%) & 0.15 & 0.00 \\
\hline L-Thr (\%) & 0.18 & 0.00 \\
\hline L-Trp (\%) & 0.04 & 0.00 \\
\hline L-Val (\%) & 0.13 & 0.00 \\
\hline Vitamin and mineral premix ${ }^{2}(\%)$ & 0.50 & 0.50 \\
\hline Total (\%) & 100.00 & 100.00 \\
\hline \multicolumn{3}{|l|}{ Calculated compositions } \\
\hline $\mathrm{DE}(\mathrm{MJ} / \mathrm{kg})$ & 14.05 & 14.20 \\
\hline ME (MJ/kg) & 13.60 & 13.74 \\
\hline Crude protein (\%) & 16.47 & 15.56 \\
\hline Digestible Lys (\% & 1.09 & 0.67 \\
\hline Digestible Met:Lys ratio & 0.34 & 0.34 \\
\hline Digestible Met+Cys:Lys ratio & 0.55 & 0.70 \\
\hline Digestible Thr:Lys ratio & 0.60 & 0.72 \\
\hline Digestible Trp:Lys ratio & 0.17 & 0.22 \\
\hline Digestible Val:Lys ratio & 0.65 & 0.88 \\
\hline $\mathrm{Ca}(\%)$ & 0.73 & 0.73 \\
\hline Digestible P (\%) & 0.35 & 0.35 \\
\hline
\end{tabular}

1) $A A+$, basal diet with amino acid supplementation; $A A-$, basal diet without amino acid supplementation.

2) Premix provided the following per kg of complete diet for growing pigs: vitamin $A$, 5,512 IU; vitamin $D_{31}, 2,200 \mathrm{IU}$; vitamin $\mathrm{E}, 30 \mathrm{IU}$; vitamin $\mathrm{K}_{3,} 2.2 \mathrm{mg}$; vitamin $\mathrm{B}_{12}$ $27.6 \mu$; riboflavin, $4.0 \mathrm{mg}$; pantothenic acid, $14.0 \mathrm{mg}$; niacin, $30.0 \mathrm{mg}$; choline chloride, $400.0 \mathrm{mg}$; folacin, $0.7 \mathrm{mg}$; thiamine $1.5 \mathrm{mg}$; pyridoxine $3.0 \mathrm{mg}$; biotin, $\left.44.0 \mu \mathrm{g} ; \mathrm{Mn}(\mathrm{MnO}), 40.0 \mathrm{mg} ; \mathrm{Fe}_{(\mathrm{FeSO}} \cdot \mathrm{H}_{2} \mathrm{O}\right), 75.0 \mathrm{mg} ; \mathrm{Zn}(\mathrm{ZnO}), 75.0 \mathrm{mg} ; \mathrm{Cu}$ $\left(\mathrm{CuSO}_{4} \cdot 5 \mathrm{H}_{2} \mathrm{O}\right), 100.0 \mathrm{mg} ; \mathrm{I}(\mathrm{KI}), 0.3 \mathrm{mg} ; \mathrm{Se}\left(\mathrm{Na}_{2} \mathrm{SeO}_{3}\right), 0.3 \mathrm{mg}$.

40; the MIU (the sum of moisture, insoluble impurities and unsaponifiable matter) value was acquired by AOCS Ca $2 \mathrm{c}-25$ (moisture), AOCS Ca 3-46 (insoluble impurities), and AOCS Ca 6a-40 (unsaponifiable matter); the peroxide value was acquired by AOCS Cd 8b-90; the hexanal value was acquired by AOCS ; the total tocopherols value was acquired by AOCS Ce 8-89. Moreover, the iodine value (IV) was calculated using the fatty acid profiles following the equation proposed by Mireia et al [22]: IV $=(\mathrm{C} 16: 1 \times 0.95)+(\mathrm{C} 18: 1 \times 0.86)+(\mathrm{C} 18$ : $2 \times 1.732)+(\mathrm{C} 18: 3 \times 2.616)+(\mathrm{C} 20: 1 \times 0.795)+(\mathrm{C} 20: 2 \times 1.57)+$ $(\mathrm{C} 20: 3 \times 2.38)+(\mathrm{C} 20: 4 \times 3.19)+(\mathrm{C} 20: 5 \times 4.01)+(\mathrm{C} 22: 4 \times 2.93)+$ $(\mathrm{C} 22: 5 \times 3.68)+(\mathrm{C} 22: 6 \times 4.64)$.

All diets and fecal samples were analyzed for dry matter (DM; method 934.01, Association of Official Analytical Chemists (AOAC, 2005), acid-hydrolyzed ether extract (AEE; method 954.02, AOAC, 2005), and crude protein (CP; method
Table 2. Analyzed chemical compositions and characteristics of the soybean oil (\%, as-fed basis)

\begin{tabular}{lc}
\hline Items & Soybean oil \\
\hline Fatty acids (\% of total fat) & \\
C14:0 & 0.09 \\
C16:0 & 11.09 \\
C16:1 & 0.10 \\
C17:0 & 0.10 \\
C18:0 & 4.16 \\
C18:1 & 22.71 \\
C18:2 & 52.87 \\
C18:3 & 6.48 \\
C20:0 & 0.38 \\
C20:1 & 0.20 \\
C21:0 & 0.10 \\
C22:0 & 0.40 \\
C23:0 & 0.59 \\
C24:0 & 0.18 \\
Other fatty acids & 0.41 \\
SFA (\%) & 17.09 \\
UFA (\%) & 82.37 \\
MUFA & 23.01 \\
PUFA (\%) & 59.35 \\
U:S & 4.82 \\
MIU (\%) & 0.32 \\
FFA (\%) & 0.10 \\
Peroxide value (mEq/kg) $\%)$ & 128 \\
p-Anisidine value (mg/kg) & 1.55 \\
Hexanal (mg/kg) & 1.06 \\
Total tocopherols (mg/kg) & 2.65 \\
\hline Aldata he $\%$ ) & 710 \\
\hline
\end{tabular}

All data are the results of analysis conducted in duplicate.

SFA, saturated fatty acids; UFA, unsaturated fatty acids; MUFA, monounsaturated fatty acids; PUFA, polyunsaturated fatty acids; U:S, the ratio of UFA to SFA; MIU, the sum of moisture, insoluble impurities and unsaponifiable matter; FFA, free fatty acids.

1) IV: iodine value, which was calculated using the fatty acid profile data following the equation proposed by Mireia et al [22]: IV $=(\mathrm{C} 16: 1 \times 0.95)+(\mathrm{C} 18: 1 \times 0.86)+$ $(\mathrm{C} 18: 2 \times 1.732)+(\mathrm{C} 18: 3 \times 2.616)+(\mathrm{C} 20: 1 \times 0.795)+(\mathrm{C} 20: 2 \times 1.57)+(\mathrm{C} 20: 3 \times 2.38)$ $+(\mathrm{C} 20: 4 \times 3.19)+(\mathrm{C} 20: 5 \times 4.01)+(\mathrm{C} 22: 4 \times 2.93)+(\mathrm{C} 22: 5 \times 3.68)+(\mathrm{C} 22: 6 \times 4.64)$.

990.03, AOAC, 2005), and all urine samples were analyzed for CP (method 990.03, AOAC, 2005) [23]. In addition, the gross energy (GE) of SO, diets, feces and urine samples were measured using an Automatic Isoperibol Oxygen Bomb Calorimeter (parr 1281 Calorimeter; Parr Instrument Co., Moline, IL, USA) using benzoic acid as a standard.

\section{Calculation}

The DE content of the diet was calculated as the difference between the total GE intake (MJ/kg of DM) and the GE content in feces $(\mathrm{MJ} / \mathrm{kg}$ of $\mathrm{DM})$. The ME content of the diet was calculated as the difference between the DE content in diet $(\mathrm{MJ} / \mathrm{kg}$ of DM) and the GE content in urine (MJ of DM). The apparent total tract digestibility (ATTD) of GE, DM, AEE, 
and $\mathrm{CP}$ was calculated using the following equation: ATTD $(\%)=\left(\left[\mathrm{F}_{\text {in }}-\mathrm{F}_{\text {out }}\right] / \mathrm{F}_{\text {in }}\right) \times 100$, where $\mathrm{F}_{\text {in }}$ is the nutrient component (GE, DM, AEE, or CP) in feed intake, and $\mathrm{F}_{\text {out }}$ is the corresponding nutrient component in feces. In the difference method, the $\mathrm{DE}$ and $\mathrm{ME}$ value of $\mathrm{SO}$ was calculated using the following equations: $\mathrm{DE}(\mathrm{MJ} / \mathrm{kg})=\left(\mathrm{DE}_{\text {diet }}-\mathrm{DE}_{0} \times[1-\mathrm{x}]\right) / \mathrm{x}$, and $\mathrm{ME}(\mathrm{MJ} / \mathrm{kg})=\left(\mathrm{ME}_{\text {diet }}-\mathrm{ME}_{0} \times[1-\mathrm{x}]\right) / \mathrm{x}$, where $\mathrm{DE}_{\text {diet }}$ and $\mathrm{ME}_{\text {diet }}$ are the $\mathrm{DE}$ and $\mathrm{ME}$ values of the experimental diets, $\mathrm{DE}_{0}$ and $\mathrm{ME}_{0}$ are the $\mathrm{DE}$ and $\mathrm{ME}$ values of the basal diets, and $\mathrm{x}$ is the inclusion levels of SO. In the regression method, the predication equations of DE and ME were established using linear regression with the inclusion ratios of $0 \%, 5 \%$, and $10 \%$. The energy values of SO were estimated using the prediction equations when $\mathrm{x}=1$.

\section{Statistical analysis}

Data were checked for normality using the UNIVERIATE procedure of SAS (SAS Institute Inc., Cary NC, USA), and analyzed by two-way analysis of variance using general linear model procedure of SAS. The statistical model included the main effects of SO inclusion level, AA supplementation, and their interaction, with individual pig as the experimental unit. Treatment means were separated using LSMEANS statement of SAS, and were adjusted using Duncan's multiple range test. Regression equations to estimate the $\mathrm{DE}$ and $\mathrm{ME}$ values of $\mathrm{SO}$ were developed using the REG procedure of SAS. The
$\mathrm{DE}$ and $\mathrm{ME}$ values of $\mathrm{SO}$ then were estimated by solving the prediction equations when the inclusion level of $\mathrm{SO}$ was equal to $100 \%$. The CLB statement of SAS was used to determine the $95 \%$ confidence interval in the regression method. Differences were considered significant at $\mathrm{p}<0.05$, whereas 0.05 $\leq \mathrm{p} \leq 0.10$ were considered statistical trends.

\section{RESULTS}

All pigs remained healthy throughout the experiment and readily consumed their diets. Both feces and urine samples were successfully collected from all pigs.

\section{Energy content, nutrient digestibility, and nitrogen balance in diets}

The effects of SO inclusion level and AA supplementation on energy content, nutrient digestibility and nitrogen $(\mathrm{N})$ balance of experimental diets are shown in Table 3. No interaction between $\mathrm{SO}$ inclusion level and AA supplementation was observed for all dietary parameters measured.

Both SO inclusion and AA supplementation significantly affected GE output in urine, but did not affect GE output in feces. Dietary SO addition (5\% or 10\%) significantly increased GE output in urine $(\mathrm{p}=0.01)$, but dietary AA supplementation significantly decreased GE output in urine $(p=0.01)$. The DE and ME content of the diets significantly improved

Table 3. Effects of soybean oil (SO) inclusion level and amino acid (AA) supplementation on energy content, nutrient digestibility and nitrogen (N) balance of the experimental diets in growing pigs (as-fed basis)

\begin{tabular}{|c|c|c|c|c|c|c|c|c|c|}
\hline \multirow{2}{*}{ Items } & \multicolumn{2}{|c|}{ AA addition } & \multicolumn{3}{|c|}{ SO Inclusion level (\%) } & \multirow{2}{*}{ SEM } & \multicolumn{3}{|c|}{$p$-value } \\
\hline & $\mathrm{AA}+$ & AA- & 0 & 5 & 10 & & AA addition & Inclusion level & Interaction \\
\hline \multicolumn{10}{|l|}{ Energy content } \\
\hline GE in feces (MJ/kg) & 1.93 & 2.04 & 1.96 & 2.11 & 1.89 & 0.09 & 0.17 & 0.09 & 0.96 \\
\hline GE in urine $(\mathrm{MJ} / \mathrm{kg})$ & $0.18^{b}$ & $0.25^{\mathrm{a}}$ & $0.17^{b}$ & $0.24^{\mathrm{a}}$ & $0.25^{\mathrm{a}}$ & 0.03 & 0.01 & 0.01 & 0.81 \\
\hline $\mathrm{DE}(\mathrm{MJ} / \mathrm{kg})$ & 15.50 & 15.55 & $14.45^{c}$ & $15.46^{\mathrm{b}}$ & $16.68^{\mathrm{a}}$ & 0.09 & 0.59 & $<0.01$ & 0.25 \\
\hline ME/DE (\%) & $98.83^{\mathrm{a}}$ & $98.40^{b}$ & 98.86 & 98.48 & 98.52 & 0.17 & $<0.01$ & 0.07 & 0.84 \\
\hline \multicolumn{10}{|l|}{$\operatorname{ATTD}(\%)$} \\
\hline GE & 88.52 & 88.37 & $87.51^{\mathrm{c}}$ & $88.04^{b}$ & $89.60^{\mathrm{a}}$ & 0.25 & 0.27 & $<0.01$ & 0.93 \\
\hline DM & 89.72 & 90.15 & $89.09^{b}$ & $90.28^{\mathrm{a}}$ & $90.44^{\mathrm{a}}$ & 0.16 & 0.10 & $<0.01$ & 0.21 \\
\hline $\mathrm{OM}$ & 91.08 & 91.70 & $90.37^{b}$ & $91.91^{\mathrm{a}}$ & $91.89^{\mathrm{a}}$ & 0.15 & 0.11 & $<0.01$ & 0.19 \\
\hline Urinary N excretion & $5.68^{b}$ & $8.52^{\mathrm{a}}$ & 6.55 & 7.21 & 7.55 & 0.30 & 0.02 & 0.62 & 0.12 \\
\hline $\mathrm{N}$ retention & $17.72^{\mathrm{a}}$ & $13.97^{b}$ & $17.64^{\mathrm{a}}$ & $15.40^{b}$ & $14.51^{c}$ & 0.32 & 0.04 & 0.04 & 0.18 \\
\hline ATTD of $N$ & 87.09 & 86.65 & $86.96^{b}$ & $85.56^{c}$ & $88.10^{\mathrm{a}}$ & 0.21 & 0.19 & 0.04 & 0.21 \\
\hline
\end{tabular}

Data are means of six observations.

SEM, standard error of the mean; GE, gross energy; DE, digestible energy; ME, metabolizable energy; ATTD, apparent total tract digestibility; DM, dry matter; OM, organic matter; AEE, acid-hydrolyzed ether extract; BW, body weight.

${ }^{a-c}$ Means within a row without a common lower-case letter differs significantly $(p<0.05)$. 
as dietary SO inclusion level increased $(\mathrm{p}<0.01)$, but were not affected by $\mathrm{AA}$ addition. The $\mathrm{ME} / \mathrm{DE}$ ratio increased with AA supplementation $(\mathrm{p}<0.01)$, meanwhile, there was a tendency for the ME/DE ratio $(p=0.07)$ to decrease with SO inclusion level.

There was a tendency for AA supplementation to increase ATTD of DM $(p=0.10)$ and AEE $(p=0.09)$ in diets. Moreover, the ATTD of GE, DM, OM, and AEE increased as the SO inclusion level increased from $0 \%$ to $10 \%(\mathrm{p}<0.01)$.

For the $\mathrm{N}$ balance, the urinary $\mathrm{N}$ excretion significantly decreased $(p=0.02)$ and $\mathrm{N}$ retention significantly increased $(\mathrm{p}=0.04)$ with AA addition. Additionally, fecal $\mathrm{N}$ excretion, $\mathrm{N}$ retention and ATTD of $\mathrm{N}$ were affected by $\mathrm{SO}$ inclusion levels $(\mathrm{p}=0.04)$ where, $0 \%$ SO inclusion resulted in greater $\mathrm{N}$ retention, and $10 \%$ SO inclusion resulted in lower fecal $\mathrm{N}$ excretion and greater ATTD of $\mathrm{N}$ in diets compared to the $0 \%$ and $5 \%$ inclusion levels.

\section{The DE and ME values of SO determined using difference or regression method}

The DE and ME values of SO determined by the difference method are shown in Table 4. No interaction between SO inclusion level and AA supplementation were observed. The ME value of SO was significantly greater when $10 \%$ SO was included in diets compared to that with $5 \%$ SO inclusion ( $\mathrm{p}$ $=0.05$ ). In addition, there was a tendency for the $\mathrm{DE}$ and $\mathrm{ME}$ value of $\mathrm{SO}$ to increase with $\mathrm{AA}$ supplementation $(\mathrm{p}=0.09$ and $\mathrm{p}=0.07$, respectively), while the $\mathrm{ME} / \mathrm{DE}$ ratio was not affected by either $\mathrm{SO}$ inclusion level or AA addition.

The DE and ME values of SO determined by the regres- sion method are shown in Table 5. With AA supplementation, the estimated intercept and slope of the prediction equations for DE and ME were 14.320 and 23.700, and 14.169 and 23.000 $\mathrm{MJ} / \mathrm{kg}$, respectively $(\mathrm{p}<0.01)$, and the coefficients of determination $\left(\mathrm{R}^{2}\right)$ for the two equations was 0.95 and 0.94 . With no AA supplementation, the estimated intercept and slope of the prediction equations for $\mathrm{DE}$ and $\mathrm{ME}$ were 14.512 and 20.667 , and 14.314 and $19.617 \mathrm{MJ} / \mathrm{kg}$, respectively ( $<<0.01$ ), and the coefficients of determination $\left(\mathrm{R}^{2}\right)$ for the two equations was 0.94 and 0.93 , respectively. Therefore, the $\mathrm{DE}$ and $\mathrm{ME}$ values of SO determined by these regression equations were 38.02 and $37.17 \mathrm{MJ} / \mathrm{kg}$ with AA addition, and 35.18 and $33.93 \mathrm{MJ} / \mathrm{kg}$ without AA addition, respectively (on as-fed basis).

The DE and ME values of SO determined by the two methods are compared in Table 6. The average DE or ME value of SO calculated by the difference method were 36.76 and 35.58 $\mathrm{MJ} / \mathrm{kg}$ with AA addition, and 34.46 and $33.04 \mathrm{MJ} / \mathrm{kg}$ without AA addition, respectively (on as-fed basis), which were numerically greater than those acquired by the regression method. However, the values obtained using the difference method with $10 \%$ SO substitution fell within the $95 \%$ confidence intervals of values obtained using the linear regression method, but these two methods were not equivalent when using 5\% SO substitution, with greater values obtained from the regression method.

\section{DISCUSSION}

In this study, we intended to test whether the $\mathrm{DE}$ and $\mathrm{ME}$

Table 4. Energy content of soybean oil (SO) in growing pigs determined by the difference method (as-fed basis)

\begin{tabular}{|c|c|c|c|c|c|c|c|c|}
\hline \multirow{2}{*}{ Items } & \multicolumn{2}{|c|}{ AA addition } & \multicolumn{2}{|c|}{ SO inclusion level (\%) } & \multirow{2}{*}{ SEM } & \multicolumn{3}{|c|}{$\mathrm{p}$-value } \\
\hline & $\mathrm{AA}+$ & $A A-$ & 5 & 10 & & AA addition & Inclusion level & Interaction \\
\hline $\mathrm{DE}(\mathrm{MJ} / \mathrm{kg})$ & 36.76 & 34.46 & 34.57 & 36.65 & - & 0.09 & 0.12 & 0.65 \\
\hline ME (MJ/kg) & 35.58 & 33.04 & 33.01 & 35.61 & 0.73 & 0.07 & 0.05 & 0.53 \\
\hline ME/DE (\%) & 96.73 & 95.83 & 95.42 & 97.13 & 0.59 & 0.46 & 0.17 & 0.78 \\
\hline
\end{tabular}

Data are means of six observations.

SEM, standard error of the mean; $D E$, digestible energy; $M E$, metabolizable energy; $A A$, amino acid.

Table 5. Energy content of soybean oil (SO) in growing pigs determined by the regression method (as-fed basis)

\begin{tabular}{|c|c|c|c|c|c|c|c|c|}
\hline \multirow{2}{*}{ Items } & \multirow{2}{*}{ Regression equations $^{11}$} & \multirow{2}{*}{$\mathbf{R}^{2}$} & \multirow{2}{*}{ RMSE } & \multicolumn{2}{|c|}{ Intercept } & \multicolumn{2}{|c|}{ Slope } & \multirow{2}{*}{ - When $\mathrm{x}=1$, estimation of $\mathrm{DE}$ or $\mathrm{ME}$} \\
\hline & & & & SEM & $\mathrm{p}$-value & SEM & $\mathrm{p}$-value & \\
\hline \multicolumn{9}{|l|}{$\mathrm{AA}+$} \\
\hline $\mathrm{DE}$ & $y=14.320+23.700 x$ & 0.95 & 0.22 & 0.08 & $<0.01$ & 1.27 & $<0.01$ & 38.02 \\
\hline ME & $y=14.169+23.000 x$ & 0.94 & 0.24 & 0.09 & $<0.01$ & 1.38 & $<0.01$ & 37.17 \\
\hline \multicolumn{9}{|l|}{ AA- } \\
\hline $\mathrm{DE}$ & $y=14.512+20.667 x$ & 0.94 & 0.22 & 0.08 & $<0.01$ & 1.29 & $<0.01$ & 35.18 \\
\hline ME & $y=14.314+19.617 x$ & 0.93 & 0.23 & 0.09 & $<0.01$ & 1.35 & $<0.01$ & 33.93 \\
\hline
\end{tabular}

RMSE, root of the mean square error; SEM, standard error of the mean; $A A$, amino acid; $D E$, digestible energy; $M E$, metabolizable energy.

${ }^{1)}$ In equation $y=a x+b, y=D E$ or ME values of diet $(M J / k g), x=$ inclusion level of soybean oil. 
Table 6. Comparison of the energy content (MJ/kg) of soybean oil in growing pigs determined by difference method and regression method with $5 \%$ or $10 \%$ soybean oil (SO) included in diets (as-fed basis)

\begin{tabular}{|c|c|c|c|c|c|c|c|c|}
\hline \multirow{2}{*}{ Items } & \multicolumn{2}{|c|}{$\begin{array}{l}\text { Difference method with } \\
5 \% \text { dietary SO inclusion }\end{array}$} & \multicolumn{2}{|c|}{$\begin{array}{l}\text { Difference method with } 10 \% \\
\text { dietary SO inclusion }\end{array}$} & \multicolumn{2}{|c|}{ Regression method } & \multicolumn{2}{|c|}{$\begin{array}{l}\text { 95\% Confidence interval from the } \\
\text { regression method }\end{array}$} \\
\hline & $\mathrm{AA}+$ & AA- & $\mathrm{AA}+$ & AA- & $\mathrm{AA}+$ & AA- & $\mathrm{AA}+$ & AA- \\
\hline DE & 35.42 & 33.71 & 38.09 & 35.21 & 38.02 & 35.18 & $35.41-40.63$ & $32.53-37.82$ \\
\hline ME & 33.91 & 32.10 & 37.25 & 33.97 & 37.17 & 33.93 & $34.33-40.00$ & $31.16-36.70$ \\
\hline
\end{tabular}

$A A$, amino acid; $D E$, digestible energy; $M E$, metabolizable energy.

contents of SO were affected by SO inclusion level and AA supplementation in basal diet, and compare the determination methodologies (the difference method vs the regression method). For the dietary parameters tested, the GE output in urine and the urinary $\mathrm{N}$ excretion in pigs fed the AA supplementation diets were lower compared with those fed diets without sufficient AA supplementation, despite greater protein intake. These results were not in accordance with the previous literature, which reported that urine $\mathrm{N}$ excretion was greater with higher dietary protein intake $[15,16]$. This phenomenon could be attributed to the unbalanced AA profile in diets when there was not sufficient AA supplementation, which led to the low utilization efficiency of AAs. As a result, addition of crystalline AA is encouraged in swine diets to improve the dietary $\mathrm{N}$ retention and reduce $\mathrm{N}$ excretion. Compared to the effect of AA addition, the parameters of dietary energy and $\mathrm{N}$ balance were more influenced by $\mathrm{SO}$ inclusion level, which was consistent with previous studies [15, 16]. As an ingredient with high energy content and energy digestibility, it is reasonable that dietary $\mathrm{SO}$ addition can easily facilitate the utilization efficiency of energy. For the other feed ingredients, such as wheat, soybean meal and wheat bran, previous studies showed no differences in GE intake and fecal and urinary GE output among all the treatments, indicating that the energy intake and output were not different as the inclusion level of ingredients changed or without AA addition $[16,24]$. It's not consistent with the current research of SO, indicating that the AA profile in these ingredients could cover up the effect of imbalanced AA profile in basal diet when there was no AA supplementation, and the low inclusion level of SO enlarged this effect when calculated using the difference method. Moreover, fecal N excretion decreased with increased inclusion level of SO, which companied with declined dietary CP level. A similar trend was observed in the studies of Su [15] and Jørgensen and Fernandez [18]. The improved ATTD of N agreed with a report that higher inclusion levels of SO improved the digestibility of $\mathrm{CP}$, and may be explained by a reduction in digesta passage rate [25].

The SO inclusion level had a clear effect on the digestibility of GE, DM, OM, and AEE, and the effect was similar to that reported in other studies. The improvement in the nutrient digestibility when lipid was added to pig diets was attributed to a chime flow rate [25]. In addition, the increase in ATTD of AEE with increasing dietary lipid level was also reported when SO [15], corn oil [14] and rapeseed oil [26] were used. On the other hand, AA supplementation of the basal diet had little influence on ATTD of nutrients, which may be due to the higher digestibility of SO. Moreover, in the current study, the diets were formulated with premix containing $100 \mathrm{mg} / \mathrm{kg} \mathrm{Cu}$, which had exceeded the suggested supplemental level of copper source in EU (EU Regulation $2018 / 1039$ suggested a copper source level of $25 \mathrm{mg} / \mathrm{kg}$ or lower for pigs after $20 \mathrm{~kg}$ ). The high $\mathrm{Cu}$ feeding may lead to the overestimation of the DM and GE digestibility in diets, since previous research reported that the digestibility of DM and GE increased with the addition of $\mathrm{Cu}$ in the corn-soy $\operatorname{diet}[27]$.

The DE and ME values of SO determined using the difference method were more affected by the $\mathrm{SO}$ inclusion level, than AA supplementation of the basal diet, especially for ME value of $\mathrm{SO}$. Although not statistically different, the $\mathrm{DE}$ and ME values of SO were numerically higher at the $10 \%$ inclusion level compared to the $5 \%$ inclusion level, while the previous reports using the corn-soybean meal basal diet showed significant results $[15,28]$. Furthermore, although not significant, the ME/DE ratio of $\mathrm{SO}$ in diets with AA supplementation was numerically greater than that in diets without AA supplementation, which may be due to the lower GE output in urine when AA were added in the basal diet.

In the current study, both the difference and regression method were used to acquire the $\mathrm{DE}$ and $\mathrm{ME}$ value of $\mathrm{SO}$. The $\mathrm{DE}$ and $\mathrm{ME}$ values of $\mathrm{SO}$ determined with the regression method were similar to the values determined with the difference method when the inclusion level of SO was $10 \%$, and is similar to that reported in other published works $[2,9,15$, 17]. Actually, in the regression method, the relationship between the energy values (DE or ME) and the inclusion levels of $\mathrm{SO}$ were not exactly linear (i.e. R2 was not equal to 1 ) which is an assumption of the model. This may explain the disparity in $\mathrm{DE}$ and $\mathrm{ME}$ values of $\mathrm{SO}$ between the methods, which was also discussed by Zhao [16] and Su [15]. The $\mathrm{DE}$ and $\mathrm{ME}$ values of $\mathrm{SO}$ were greater when pigs fed $\mathrm{AA}$ supplemental diets compared to diets without AA supple- 
mentation using both difference and regression methods, which could be explained by the effect of balanced AA profile on energy utilization efficiency.

Some contradictions of SO substitution rate were unavoidable when difference method was used in detection of the DE and ME values. In previous research, Villamide [29] thought a higher standard error would occur with difference method in a low SO substitution rate test diet, though the 5\% inclusion level is more important commercially. However, a high substitution rate can improve the accuracy of energy determination, but can cause a nutrient imbalance and influence the nutrient digestibility in diet. Our research found that energy values determined with the difference method at $10 \%$ SO substitution were all within the $95 \%$ confidence interval of the values determined with the regression method. Similar energy values between the 2 methods were not observed at the 5\% SO substitution, indicating that the choice of experimental method in feed evaluation may affect the feed energy value, when low dietary lipid inclusion levels are used (e. g. lower than 5\%), so did the dietary crystalline AA supplementation. Although the regression method is commonly used to determine energy value of oil $[1,9,12,18]$, it is time-consuming and costly. Moreover, more experimental animals are required in the regression method to fulfill the graded levels of the test ingredients, increasing the influential factors of the experiment. From the results of the current research, the determined $\mathrm{DE}$ and $\mathrm{ME}$ values of $\mathrm{SO}$ at $10 \%$ inclusion level using difference method were similar to those using regression method, thus could act as a substitution for the regression method, but not for SO at 5\% inclusion level.

\section{CONCLUSION}

In summary, the $\mathrm{DE}$ and $\mathrm{ME}$ values of $\mathrm{SO}$ are affected by the inclusion level of soybean oil but not AA supplementation. There is no interaction between AA supplementation and SO addition on energy values of $\mathrm{SO}$ and dietary nutrient digestibility in the range of $0 \%$ to $10 \%$. Therefore, with $5 \%$ or less $\mathrm{SO}$ addition there should be no concern about the effects of AA supplementation on energy values of $\mathrm{SO}$ in actual practice. Moreover, the difference method can substitute the traditionally-used regression method to determine the $\mathrm{DE}$ and $\mathrm{ME}$ values of SO when the inclusion level is 10\%, but not at 5\% inclusion level.

\section{CONFLICT OF INTEREST}

We certify that there is no conflict of interest with any financial organization regarding the material discussed in the manuscript.

\section{ACKNOWLEDGMENTS}

This research was financially supported by the Fundamental Research Funds for the Central Universities (2018QC061).

\section{REFERENCES}

1. Wiseman J, Cole DJA, Hardy B. The dietary energy values of soya-bean oil, tallow and their blends for growing/finishing pigs. Anim Sci 1990;50:513-8. https://doi.org/10.1017/S000 3356100005006

2. Powles J, Wiseman J, Cole DJA, Jagger S. Prediction of the apparent digestible energy value of fats given to pigs. Anim Sci 1995;61:149-54. https://doi.org/10.1017/S13577298000 13631

3. Cervantes-Pahm SK, Stein HH. Effect of dietary soybean oil and soybean protein concentration on the concentration of digestible amino acids in soybean products fed to growing pigs. J Anim Sci 2008;86:1841-9. https://doi.org/10.2527/jas. 2007-0721

4. Adedokun SA, Pescatore AJ, Ford MJ, Jacob JP, Helmbrecht A. Examining the effect of dietary electrolyte balance, energy source, and length of feeding of nitrogen-free diets on ileal endogenous amino acid losses in broilers. Poult Sci 2017;96: 3351-60. https://doi.org/10.3382/ps/pex159

5. Niyazov SA, Kalnitsky BD. Effects of low-protein diets with different levels of essential amino acids and metabolizable energy on productivity and metabolic processes in pigs. Russ Agric Sci 2018;44:75-9. https://doi.org/10.3103/S1068367 418010135

6. Gous RM, Faulkner AS, Swatson HK. The effect of dietary energy:protein ratio, protein quality and food allocation on the efficiency of utilisation of protein by broiler chickens. Br Poult Sci 2018;59:100-9. https://doi.org/10.1080/00071668. 2017.1390211

7. Niyazov SA, Kalnitsky BD. Productivity and nitrogen metabolism in pigs fed low-protein diets with various levels of essential amino acids. Russ Agric Sci 2014;40:470-4. https://doi. org/10.3103/S1068367414060184

8. Sauvant D, Perez JM, Tran G. Tables of composition and nutritional value of feed materials: pig, poultry, sheep, goats, rabbits, horses, fish. Paris, France: Wageningen Academic Publishers, Wageningen, the Netherlands and INRA; 2004.

9. Su YB, Bi XH, Ma XK, et al. Determination and prediction of the digestible and metabolizable energy content of lipid sources fed to growing pigs. Anim Feed Sci Technol 2015; 209:119-27. https://doi.org/10.1016/j.anifeedsci.2015.07.004

10. Rosero DS, Odle J, Arellano C, Boyd RD, Van HE. Development of prediction equations to estimate the apparent digestible energy content of lipids when fed to lactating sows. J Anim Sci 2015;93:1165-76. https://doi.org/10.2527/jas.2014-8402

11. Committee on Nutrient Requirements of Swine, National 
Research Council. Nutrient requirements of swine. 11th ed. Washington, DC, USA: National Academy Press; 2012.

12. Allee GL, Hines RH. Influence of fat level and calorie: protein ratio on performance and carcass composition of young pigs. In: Swine day; 1972 Nov 2; Manhattan, KS, USA. Manhattan, KS, USA: Kansas State University, Agricultural Experiment Station and Cooperative Extension Service; 1972. p. 29-32.

13. Kronfeld DS. Dietary fat affects heat production and other variables of equine performance, under hot and humid conditions. Equine Vet J Suppl 1996;28:24-34. https:/doi. org/10.1111/j.2042-3306.1996.tb05028.x

14. Kil DY, Sauber TE, Jones DB, Stein HH. Effect of the form of dietary fat and the concentration of dietary neutral detergent fiber on ileal and total tract endogenous losses and apparent and true digestibility of fat by growing pigs. J Anim Sci 2010;88:2959-67. https://doi.org/10.2527/jas.2009-2216

15. Su YB, She Y, Huang Q, et al. The effect of inclusion level of soybean oil and palm oil on their digestible and metabolizable energy content determined with the difference and regression method when fed to growing pigs. Asian-Australas J Anim Sci 2015;28:1751-9. https://doi.org/10.5713/ajas.14. 0498

16. Zhao JB, Shi CX, Li ZC, et al. Effects of supplementary amino acids on available energy of soybean meal determined by difference and regression methods fed to growing pigs. Anim Sci J 2018;89:404-11. https://doi.org/10.1111/asj.12940

17. Wiseman J, Cole DJA. The digestible and metabolizable energy of two fat blends for growing pigs as influenced by level of inclusion. Anim Sci 1987;45:117-22. https://doi.org/10.1017/ S0003356100036709

18. Jørgensen H, Fernández JA. Chemical composition and energy value of different fat sources for growing pigs. Acta Agric Scand A Anim Sci 2000;50:129-36. https://doi.org/10.1080/ 090647000750014250

19. Adeola O. Digestion and balance techniques in pigs. In: Lewis AJ, Southern LL, editors. Swine nutrition. 2nd ed. New York, USA: CRC Press; 2001. p. 903-16.

20. Sukhija PS, Palmquist DL. Rapid method for determination of total fatty acid content and composition of feedstuffs and feces. J Agric Food Chem 1988;36:1202-6. https://doi.org/ 10.1021/jf00084a019

21. AOCS. Official methods and recommended practices of the American Oil Chemists' Society, 6th edn. Urbana IL, USA: AOCS; 2011.

22. Mireia O, Gemma V, Jordi E, et al. Determination of the iodine value of biodiesel using 1H NMR with 1,4-dioxane as an internal standard. Fuel 2010;89:3489-92. https://doi.org/10. 1016/j.fuel.2010.06.016

23. AOAC. Official methods of analysis. Association of Official Analytical Chemists, 18th edn. Washington DC, USA: AOAC International; 2005.

24. Jaworski NW, Liu DW, Li DF, Stein HH. Wheat bran reduces concentrations of digestible, metabolizable, and net energy in diets fed to pigs, but energy values in wheat bran determined by the difference procedure are not different from values estimated from a linear regression procedure. J Anim Sci 2016;94:3012-21. https://doi.org/10.2527/jas.2016-0352

25. Mateos GG, Sell JL, Eastwood JA. Rate of food passage (transit time) as influenced by level of supplemental fat. Poult Sci 1982;61:94-100. https://doi.org/10.3382/ps.0610094

26. Jørgensen H, Jensen SK, Eggum BO. The influence of rapeseed oil on digestibility, energy metabolism and tissue fatty acid composition in pigs. Acta Agric Scand A Anim Sci 1996; 46:65-75. https://doi.org/10.1080/09064709609415854

27. Coble KF, Burnett DD, Derouchey JM, et al. Effect of diet type and added copper on growth performance, carcass characteristics, energy digestibility, gut morphology, and mucosal mRNA expression of finishing pigs. J Anim Sci 2018;96:3288-301. https://doi.org/10.1093/jas/sky196

28. Kerr BJ, Weber TE, Dozier WA, Kidd MT. Digestible and metabolizable energy content of crude glycerin originating from different sources in nursery pigs. J Anim Sci 2009;87: 4042-9. https://doi.org/10.2527/jas.2008-1676

29. Villamide MJ. Methods of energy evaluation of feed ingredients for rabbits and their accuracy. Anim Feed Sci Technol 1996;57:211-23. https://doi.org/10.1016/0377-8401(95)00 855-1 